\title{
Probiotics May Improve Serum Folate Availability in Pregnant Women: A Pilot Study
}

Andrea Ballini ${ }^{1,2}$, Luca Signorini ${ }^{3}$, Alessio Danilo Inchingolo ${ }^{4}$, Rajiv Saini ${ }^{4,5}$, Antonio Gnoni ${ }^{6}$, Salvatore Scacco ${ }^{6}$, Stefania Cantore $^{4}$, Gianna Dipalma ${ }^{4}$, Francesco Inchingolo ${ }^{4}$, Luigi Santacroce ${ }^{5,7 *}$

${ }^{1}$ Department of Biosciences, Biotechnologies and Biopharmaceutics, Campus Universitario "Ernesto Quagliariello", University of Bari "Aldo Moro", Bari, Italy; 'Department of Precision Medicine, University of Campania "Luigi Vanvitelli", Naples, Italy; ${ }^{3}$ Departmental Faculty of Medicine and Surgery, Unicamillus University, Rome, Italy; ${ }^{4}$ Department of Interdisciplinary Medicine, University of Bari "Aldo Moro", Bari, Italy; " Department of Ionian, School of Medicine, University of Bari "Aldo Moro", Bari, Italy; ${ }^{6}$ Department of Basic Medical Sciences, Neurosciences and Sense Organs, University of Bari Aldo Moro, Bari, Italy; ${ }^{7}$ Department of Clinical Disciplines, School of Technical Medical Sciences, "A. Xhuvani” University, Elbasan, Albania

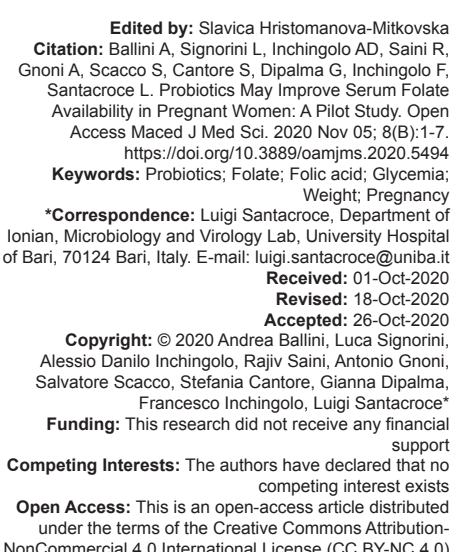

Edited by: Slavica Hristomanova-Mitkovska Edited by: Slavica Hristomanova-Mitkovska
Citation: Ballini A, Signorini L, Inchingolo AD, Saini R Citation: Ballini A, Signorini L, Inchingolo AD, Saini R, Santacroce L. Probiotics May Improve Serum Folate Santacroce L. Probiotics May Improve Serum Folate Availability in Pregnant Women: A Pilot Study. Open
Access Maced J Med Sci. 2020 Nov 05; 8(B):1-7. https://doi.org/10.3889/oamjms.2020.5494
hel. Keywords: Probiotics; Folate; Folic acid; Glycemia Weight; Pregnancy
${ }^{*}$ Correspondence: Luigi Santacroce, Department of Ionian, Microbiology and Virology Lab, University Hospita of Bari, 70124 Bari, Italy. E-mail: luigi.santacroce@uniba.it Received: 01-Oct-2020 Revised: $18-$ Oct-2020 Copyright: ๑ 2020 Andrea Ballini, Lca- Signorini Alessio Danilo Inchingolo, Rajiv Saini, Antonio Gnoni, Salvatore Scacco, Stefania Cantore, Gianna Dipalma Salvatore Scacco, Stefania Cantore, Gianna Dipalma,
Francesco Inchingolo, Luigi Santacroce Funding: This research did not receive any financial Competing Interests: The authors have declared that no competing interest exists Open Access: This is an open-access article distribute under the terms of the Creative Commons Attribution-

\section{Abstract}

BACKGROUND: Probiotics are living microorganisms that confer a health benefit when administered in adequate amounts. There is evidence in the current literature about the importance of probiotic use in pregnancy. The early supplementation of probiotics in the perinatal and postnatal periods seems to have a positive impact on the overal mother's health and future health of infants.

AIM: Our pilot study aimed to test the ability of specific probiotics strains in combination with the kiwi-unique enzyme actinidin to improve the availability of folic acid in 20 pregnant women.

METHODS: We investigate 20 pregnant women in early (4-10 weeks) (6 patients), intermedium (11-20 weeks) (6 patients), and late (21-30 weeks) (8 patients) pregnancy.

RESULTS: Our findings show that the tested formula promotes increased concentration of serum folate in women's blood and contributes to the control of blood sugar and body weight, regardless of the gestational period (early, intermediate or late).

CONCLUSIONS: Our data support the main results reported in the scientific literature about the importance of probiotics intake in pregnancy.

\section{Introduction}

Breast milk is known to be the best form of nutrition for newborns, especially for those born preterm. Variation in the composition of fatty acids in infant feeding can influence the microbial composition of the gut. The use of prebiotics and probiotics to stimulate gut microbial composition is increasingly compelling evidence [1].

The prevalence of allergies in newborns is about $10 \%$, but it can reach $20-30 \%$ in those with a first-degree allergic relative [2], [3]. Prebiotics promote particular changes in the gastrointestinal microflora, regard composition and activity [4]. They influence immune response, and their supplementation has been proposed as a way to prevent allergic diseases but also of a different nature, as in the case of oncological diseases [2], [3], [4]. Preterm birth is the main cause of death in newborns; moreover, it represents a risk factor for adverse health outcomes: Nutritional approaches are a promising solution; among them, the use of zincfolic acid, combined iron-folate, and probiotics [5].

Numerous studies in the literature confirm that the nutrition of women in pregnancy and especially during breastfeeding influences the growth, development, and health of the baby in intrauterine and extrauterine life [6]. According to the latest data, poor nutrition during pregnancy can lead to spontaneous abortion or to a premature birth [7].

The first evidence of the importance of probiotic use in pregnancy was found on blood glucose values. Laitinen et al. [7] compared three intervention groups in a Finnish population of 256 pregnant women. The different groups followed three different models of nutrition: The first group followed a specific diet with probiotics, a second group a diet with a placebo effect, and a third and last control group followed a single and unique placebo diet. Women received the probiotic supplementation, containing Lactobacillus and Bifidobacterium, from the 
early period to the postpartum period: In the test group, the normal diet supplemented with the use of probiotics had significantly reduced blood sugar values in the third trimester and consequently showed an improvement in insulin sensitivity [8]. Similarly, probiotics appear to show antioxidant properties as an iron-reducing activity in pregnant women [9].

The use of probiotics helps to maintain intestinal eubiosis and to control metabolic and immune changes, including the prevention of pathological situations both for the mother and the infant [10].

Our pilot study aimed to assess the benefits of the ability of specific probiotics strains in combined formula with the kiwi-unique enzyme actinidin to improve the availability of folic acid in pregnant women.

\section{Materials and Methods}

\section{Participants}

The Institutional Ethics Committee of the Faculty of Technical Medical Sciences of Elbasan "ALEKSANDËR XHUVANI" has approved the application to conduct the clinical trial in the Faculty. Title of the Protocol: Probiotics efficacy and safety in humans. Protocol identification: INTL_ALITCOOP/ Probiotics/INRES2019_w/a/c.

The study was carried out according to the Helsinki declaration and informed written consent was obtained from all the subjects.

Folate and folic acid intakes of 20 pregnant women were assessed in early (4-10 weeks) (6 patients), intermedium (11-20 weeks) (6 patients), and late (21-30 weeks) (8 patients) pregnancy. Blood concentrations of folate and unmetabolized folic acid were measured with the use of immunoassays and liquid chromatographymass spectrometry, respectively, in maternal samples in early, intermedium, and late pregnancy. Participants did not take antibiotics for $\geq 3$ months before participating in the study. Furthermore, participants did not take drugs or food supplements (e.g., folate-rich foods) that could influence the dependent variables; a health history questionnaire was provided from investigators. Prebiotic/probiotic foods (e.g., yogurt) have not been included in their diet. Participants were able to consume $450 \mathrm{~g} /$ day ( $16 \mathrm{fl}$. oz./day) of black coffee with caffeine or unsweetened black tea if used to consuming them regularly.

Targeted probiotic strains (TPS) specifically chosen for the support they can provide to pregnant and breastfeeding moms such as encouraging nutrient absorption, supporting the production of natural (nonsynthetic) folate, and breastfeeding and immune system support: Bifidobacterium infantis, Lactobacillus rhamnosus, Lactobacillus plantarum, Lactobacillus fermentum, Lactobacillus reuteri, and Lactobacillus acidophilus in combination with the kiwi-unique enzyme actinidin (Kiwifruit Powder). The formula containing 5 Billion colony forming units $†$ (CFUs) per BIO-tract ${ }^{\circledR}$ tablet, which is equivalent to 75 Billion CFU of probiotic veggie capsules. Moreover, the Kiwifruit Powder is a whole food that helps patients' probiotics colonize and naturally supports regularity, a common concern during pregnancy.

\section{Experimental design}

The tested formula (PRO-MOM Hyperbiotics, USA) contains six TPS specifically chosen for the support they can provide to pregnant and breastfeeding moms such as encouraging nutrient absorption, supporting the production of natural (non-synthetic) folate, and breastfeeding and immune system support: $B$. infantis, L. rhamnosus, L. plantarum, L. fermentum, $L$. reuteri, and $L$. acidophilus in combination with the kiwi-unique enzyme actinidin (Kiwifruit Powder). The formula containing 5 Billion CFUs† per BIO-tract ${ }^{\circledR}$ tablet, which is equivalent to 75 Billion CFU of probiotic veggie capsules. Moreover, the Kiwifruit Powder is a whole food that helps patients' probiotics colonize and naturally supports regularity, a common concern during pregnancy.

A randomized, double-blind, and placebocontrolled parallel-group investigation was applied for this study. After completing baseline measures, the participants were divided by age and month of pregnancy and randomized into one of two groups: integration with PRO-MOM Hyperbiotics, USA (1 tablet per day) (test group) or without probiotic administration (placebo group). Measurements of key outcome variables (body weight) were performed at baseline (TO) and after the 8-week treatment period (T1) within each of the three groups (early, intermediate, and late - pregnancy). All measurements were taken between 7:00 am and 11:00 am. Blood was collected at baseline and after 8 weeks of treatment for glycemic control and serum folate status.

\section{Statistical analysis}

Outcome measures were analyzed with a t-test for paired samples for pre-post differences with time as the factor using (Statistical Package for the Social Sciences for Windows, Version 11.5, Chicago, III) software to detect significant differences between pre-test and post-test scores.

\section{Results}

Furthermore, on the first visit, the participants were instructed on the objectives and methods of 
clinical trials. Subjects who agreed to participate in the study, after having signed the informed consent, were randomly included and divided into two groups: A test group using probiotics, instead, the other group of a placebo, without probiotics.

Twenty people were enrolled as follows:

a. Placebo group: 3 early, 3 intermedium, and 4 late b. $\quad$ Test group: 3 early, 3 intermedium, and 4 late.

\section{Folate values}

Serum folate concentration was measured in the placebo group and test group at T0 and T1. Laboratory values were carefully analyzed and reported in Table 1.

Table 1: Blood concentration of folate in the placebo group and test group at $\mathrm{T0}$ and $\mathrm{T} 1$.

\begin{tabular}{|c|c|c|c|c|c|c|c|}
\hline \multicolumn{4}{|c|}{ Blood concentration of folate: Placebo group } & \multicolumn{4}{|c|}{ Blood concentration of folate: Test group } \\
\hline ID & $\begin{array}{l}\text { Pregnancy } \\
\text { period }\end{array}$ & $\begin{array}{l}\text { T0 } \\
\text { (ng/ml) }\end{array}$ & $\begin{array}{l}\text { T1 } \\
\text { (ng/ml) }\end{array}$ & $\overline{\mathrm{ID}}$ & $\begin{array}{l}\text { Pregnancy } \\
\text { period }\end{array}$ & $\begin{array}{l}\text { T0 } \\
\text { (ng/ml) }\end{array}$ & $\begin{array}{l}\text { T1 } \\
\text { (ng/ml) }\end{array}$ \\
\hline EA & Early & 5.5 & 7.3 & $\mathrm{MM}$ & Early & 7 & 10 \\
\hline CB & Early & 6 & 8.8 & $A C$ & Early & 7.8 & 10.1 \\
\hline FG & Early & 7.3 & 9 & PA & Early & 6.2 & 9.1 \\
\hline IM & Intermedium & 9.9 & 11.5 & FV & Intermedium & 11.9 & 13.9 \\
\hline MT & Intermedium & 11 & 12.9 & ACC & Intermedium & 10 & 12.7 \\
\hline$R R$ & Intermedium & 12.7 & 13.9 & BG & Intermedium & 11 & 14 \\
\hline SA & Late & 16 & 18.1 & $\mathrm{KL}$ & Late & 17 & 19.8 \\
\hline FT & Late & 15.3 & 16.8 & VF & Late & 18 & 21 \\
\hline MTO & Late & 18 & 20 & DC & Late & 16.5 & 19.7 \\
\hline FP & Late & 16.9 & 19.2 & ST & Late & 19 & 21.8 \\
\hline
\end{tabular}

Moreover, serum folate values were evaluated at time T0 and T1 in placebo group and test group.

As shown in Figure $1 \mathrm{a}$, the trend of serum folate values was evaluated at time T0 and T1 in the placebo group. The results showed an increasing trend of around $16 \%$ from baseline to $\mathrm{T} 1$, since during the gestation period, folate levels increase, linked to the supplements that pregnant women usually implement in their diet.

In Figure $1 \mathrm{~b}$, the trend of serum folate values was evaluated at time T0 and T1 in the test group. The results showed a variation of blood folate levels from T0 to T1 in the test group. It should be noted that the data present at time 0 increased by about $22 \%$ at T1, a substantial increase compared to the conditions of the placebo.

In both groups, the T0 values are included in the standard ranges, which vary according to the gestation period: In the early period, folate values are slightly lower than in the intermediate and late one. Therefore, the resulting data show how prebiotic intake has been able to favor a greater increase in blood folate values.

\section{Glycemia values}

Blood glucose concentration was measured in the placebo group and test group at T0 and T1 and reported in Table 2.

Table 2: Glycemia in the placebo group and test group at TO and T1

\begin{tabular}{|c|c|c|c|c|c|c|c|}
\hline \multicolumn{4}{|c|}{ Glycemia: Placebo group } & \multicolumn{4}{|c|}{ Glycemia: Test group } \\
\hline ID & $\begin{array}{l}\text { Pregnancy } \\
\text { period }\end{array}$ & $\begin{array}{l}\text { T0 } \\
(\mathrm{mg} / \mathrm{d})\end{array}$ & $\begin{array}{l}1 \\
\text { (mg/dL) }\end{array}$ & ID & $\begin{array}{l}\text { Pregnancy } \\
\text { period }\end{array}$ & $\begin{array}{l}\text { T0 } \\
\text { (mg/dL) }\end{array}$ & $\begin{array}{l}11 \\
\text { (mg/dL) }\end{array}$ \\
\hline EA & Early & 69 & 68.9 & MM & Early & 67 & 65.3 \\
\hline $\mathrm{CB}$ & Early & 70 & 71 & AC & Early & 78 & 76 \\
\hline FG & Early & 71 & 70 & PA & Early & 77.9 & 76 \\
\hline IM & Intermedium & 67 & 66.8 & FV & Intermedium & 67.9 & 65.5 \\
\hline MT & Intermedium & 65 & 66 & ACC & Intermedium & 81 & 79.1 \\
\hline $\mathrm{RR}$ & Intermedium & 80 & 78.8 & BG & Intermedium & 79.9 & 77 \\
\hline SA & Late & 79 & 78.5 & $\mathrm{KL}$ & Late & 83.4 & 82 \\
\hline FT & Late & 76.4 & 77.7 & VF & Late & 73 & 72 \\
\hline MTO & Late & 78 & 78 & DC & Late & 75.7 & 73 \\
\hline $\mathrm{FP}$ & Late & 87.1 & 86.7 & ST & Late & 82.3 & 80.4 \\
\hline
\end{tabular}

Glycemia values were also evaluated at time T0 and T1 in placebo group and test group.

As shown in Figure $2 a$, the glucose concentration $(\mathrm{mg} / \mathrm{dL})$ does not vary substantially from T0 to T1 in the placebo group: The two lines overlap in the graph. Moreover, the obtained values are all lower than $92 \mathrm{mg} / \mathrm{dL}$, which underlines the good health condition of women enrolled in T0 that is also maintained at $\mathrm{T} 1$.

As shown in Figure $2 b$, the glucose concentration $(\mathrm{mg} / \mathrm{dL})$ slightly varies from baseline to T1 in the test group after taking the probiotics: T1 values are $2.5 \%$ lower than T0, which allows us to say that taking probiotics could help to control blood

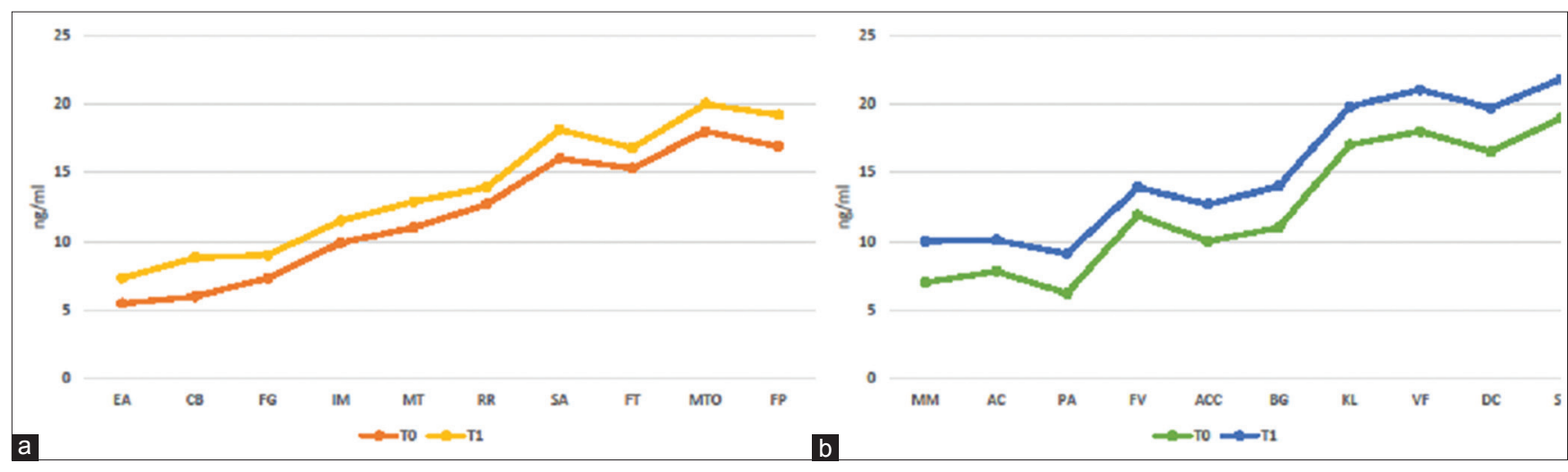

Figure 1: Serum folate concentration ( $\mathrm{ng} / \mathrm{ml})$ at time TO and T1 in placebo group and test group: (a) This graph shows the trend of serum folate values at time TO and T1 in the placebo group. There is an increasing trend from baseline TO to T1 of around 16\%; (b) the graph shows how blood folate levels vary from T0 to T1 in the test group. It should be noted that T0 values increase by about $22 \%$ at T1 that is a substantial increase if compared to the placebo one. The results show that the probiotic intake promotes the increase of folate values in the blood 


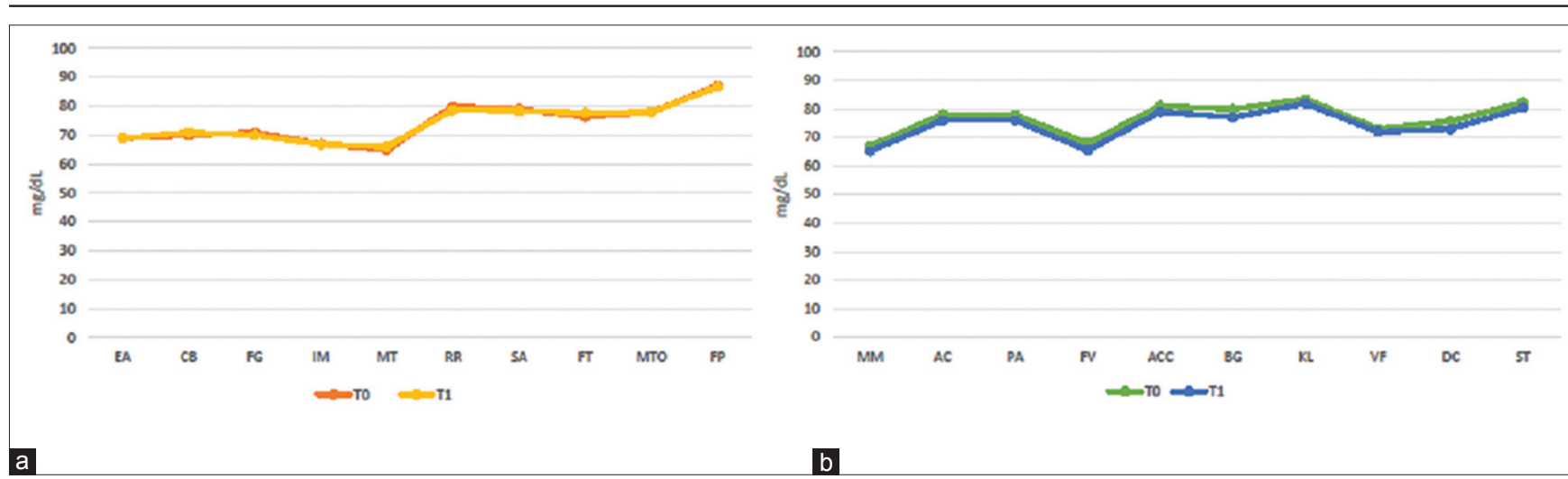

Figure 2: Blood glucose concentration ( $\mathrm{mg} / \mathrm{dL}$ ) at time T0 and T1 in placebo group and test group: (a) The graph shows the glucose values in TO and T1 in the placebo group: The two lines overlap and the trend of the graph is linear as there are no differences in the values; (b) the graph shows the glucose values in TO and T1 in the test group: Glycemia varies from baseline to T1, reducing of $2.5 \%$ that is a great result to say that taking probiotics could help to control glycemia

glucose concentration; moreover, it could be a way to prevent gestational diabetes.

\section{Weight values}

Weight values were measured in the placebo group and test group at T0 and T1. Data were carefully analyzed and reported in Table 3.

Table 3: Weight in the placebo group at T0 and T1

\begin{tabular}{|c|c|c|c|c|c|c|c|}
\hline \multicolumn{4}{|c|}{ Weight: Placebo group } & \multicolumn{4}{|c|}{ Weight: Test group } \\
\hline$\overline{\mathrm{ID}}$ & $\begin{array}{l}\text { Pregnancy } \\
\text { period }\end{array}$ & T0 (kg) & $\mathrm{T} 1(\mathrm{~kg})$ & $\overline{\mathrm{ID}}$ & $\begin{array}{l}\text { Pregnancy } \\
\text { period }\end{array}$ & T0 (kg) & $\mathrm{T} 1(\mathrm{~kg})$ \\
\hline EA & Early & 65 & 67 & MM & Early & 54 & 55.1 \\
\hline $\mathrm{CB}$ & Early & 52 & 54.6 & $A C$ & Early & 59 & 60.1 \\
\hline FG & Early & 59.4 & 61.9 & PA & Early & 70 & 72 \\
\hline IM & Intermedium & 51.5 & 53.7 & FV & Intermedium & 56 & 57.3 \\
\hline MT & Intermedium & 56 & 59 & ACC & Intermedium & 67 & 68.4 \\
\hline RR & Intermedium & 63.6 & 67 & BG & Intermedium & 65 & 66.9 \\
\hline SA & Late & 53.9 & 55.8 & $\mathrm{KL}$ & Late & 53 & 55 \\
\hline FT & Late & 61.6 & 64.2 & VF & Late & 56.8 & 58 \\
\hline MTO & Late & 59 & 61.9 & DC & Late & 64.1 & 65.8 \\
\hline FP & Late & 70 & 71.8 & ST & Late & 54.9 & 56 \\
\hline
\end{tabular}

Weight values were evaluated at time T0 and T1 in placebo group and test group.

As shown in Figure $3 a$, weight values slightly vary from baseline to $\mathrm{T} 1$ in the placebo group: There is a normal weight gain of $4 \%$ from T0 to T1 due to the physiological increase during pregnancy.

As shown in Figure $3 \mathrm{~b}$, weight values slightly vary from baseline to T1 in the test group: There is an increase of $2.5 \%$ from $\mathrm{TO}$ to $\mathrm{T} 1$, which is a minimum increase if compared to the placebo group. This result allows us to underline that the use of probiotics is also useful for weight monitoring, an important factor to safeguard fetus health.

\section{Discussion}

It is well known that imbalances in the intake of macronutrients and micronutrients during pregnancy can alter the growth and development of the fetus, predisposing it to the risk of pathologies in recent and future times [10], [11]. According to a review conducted on Cochrane, from Haider and Bhutta, a diet, in pregnant women, enriched with micronutrients with iron and folic acid and with the external integration of prebiotics has resulted in a significant reduction of infants born with low weight but also a reduction equally significant number of infants born premature and/or dead [12]. This is about a $20 \%$ lower probability of women giving birth to children who will develop inflammations, atypical diseases compared to those women who do not include the use of probiotics in their diet [13]. On a practical plan, this corresponds to 44 cases of eczema per thousand children. To suggest, it is a study published by Kalliomäki et al. in 2007 [14].

A diet during the gestational period and in the 2 months following birth, therefore, during lactation, rich in L. rhamnosus and Bifidobacterium lactis brings beneficial effects on maternal health, fetal growth, and morbidity of the baby [15]. The same use of probiotics can guarantee, even in part, good bone regeneration and prevent mothers from any pathologies related to bone and dental loss [16], [17], [18]. In fact, in a clinical study involving 208 mother/child couples, particular benefits were found after probiotics intake: There was constant maintenance of body weight in pregnant women, and an increase in length and a reduction in the incidence of diarrhea in the newborn [17].

In a recent study, $L$. plantarum A41 and L. fermentum SRK414 showed high probiotic potential and a strong impact on the bone health of pregnant women by modulating the production of pro-inflammatory cytokines and markers related to bone metabolism [18]. In line with even more recent studies, the use of translational researches in regenerative medicine, as well as the use of pharmacological nanotechnologies alongside the consumption of probiotics, can improve bone health in pregnancy by guaranteeing the right supply of calcium and micronutrients [19], [20].

According to a study conducted in 2018 and published by the World Nutritional Journal, Vitamin B12 


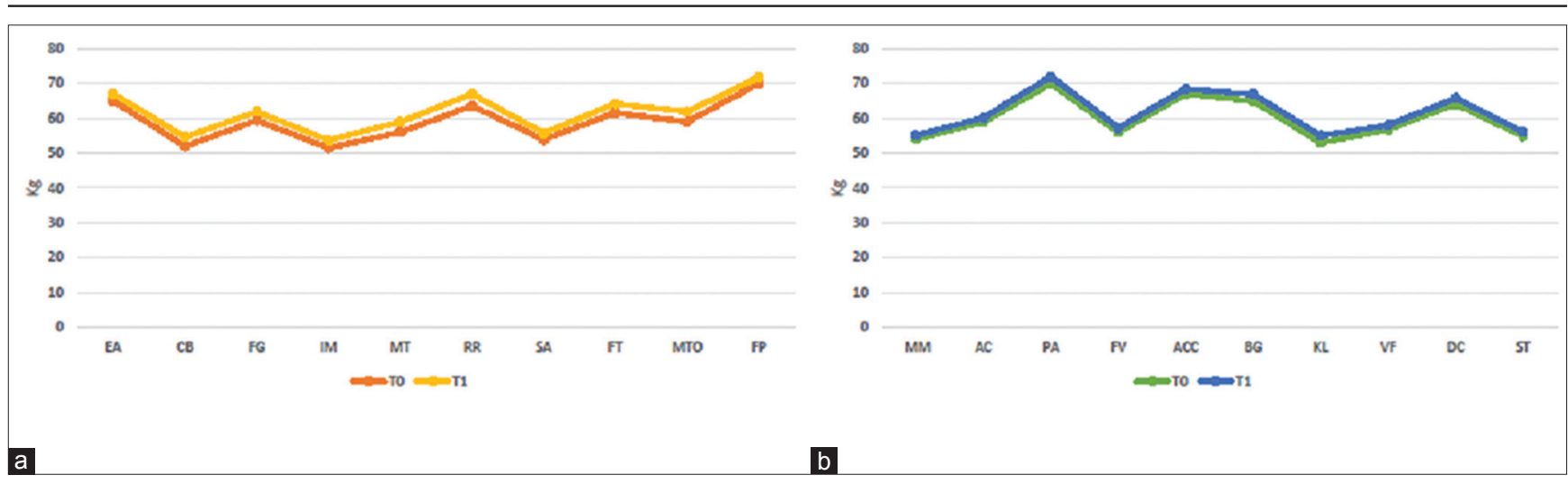

Figure 3: Weight values at time T0 and T1 in placebo group and test group: (a) The graph shows that there is a normal weight gain of 4\% from TO to T1 in placebo group, probably due to the physiological increase in pregnancy; (b) the graph shows the weight trend from T0 to T1 in pregnant women in the test group: Weight varies from baseline to T1, increasing of $2.5 \%$. Compared to the placebo group, this result means that the use of probiotics can help in the weight monitoring of pregnant women

plays an important role in preventing congenital birth defects such as malformations to hydrocephalus and spina bifida [21].

In this randomized clinical study conducted on pregnant women, it has been shown how the intake, in the three gestational quarters, of probiotics increases the serum concentration of Vitamin B12. In particular, by integrating a normal probiotic containing Bifidobacterium animalis subsp. lactis (HNO19), blood levels of Vitamins B9 and B12 appear to increase in the $2^{\text {nd }}$ and $3^{\text {rd }}$ trimester. The consumption of pre and probiotics during the periconceptional period can be a useful strategy for improving maternal Vitamin B concentrations [22]. The British Journal of Nutrition has published the results of a randomized clinical trial according to which the problem of many pregnant women to develop gestational diabetes could be solved by the use of probiotics. The study was conducted on over 250 pregnant women and the results show a reduction in glucose concentration in women who have followed the diet supplemented with probiotics of approximately $20 \%$. Glucose homeostasis guarantees optimal fetal growth with health implications before and after childbirth, both for mothers and newborns [7].

According to the results of a further study published in the Journal of Diabetes Investigation, in women with gestational diabetes, following a diet supplemented with probiotics for 4 weeks resulted in a reduction in fasting blood sugar and increased sensitivity to insulin. The study was conducted double-blind on 57 women between 24 and 28 weeks of gestation. The participants were divided into two groups; the first group was assigned a diet with probiotics containing bifidobacteria and lactobacilli, while the second group took placebo. Feeding with probiotics for 4 weeks, between the end of the second and the beginning of the third trimester of pregnancy, resulted in positive metabolic changes in favor of fasting blood sugar. In fact, there has been a drop in blood glucose value. Furthermore, these effects were not accompanied by significant differences in weight gain between the two treatment groups. The authors have consequently shown how integration with probiotics has proven safe and well-tolerated by pregnant women. Kijmanawat et al., therefore, deduced that for women with gestational diabetes, supplementation with probiotics at 24-28 weeks of pregnancy can be considered an additional treatment for glycemic control [23]. In more recent times, the use of pharmacological therapy with the advent of nanotechnologies can also further improve the health of women with gestational diabetes [24]. In recent years, there have been several studies that have focused on the beneficial effects of probiotics in different fields [25], [26], [27], [28], [29], [30], [31], [32], [33], [34].

\section{Conclusions}

Based on the resulting data, our clinical study indicates that the supplementing probiotics of PROMOM Hyperbiotics USA in the diet of pregnant women would bring numerous benefits to them, regardless of the gestational period (early, intermediate or late). In pregnant women enrolled in our study, taking probiotics favored the increased concentration of folate in the blood and contributed to the control of blood sugar and body weight. Our data confirmed and improved the main results reported in the scientific literature about the importance of probiotics intake in pregnancy.

\section{References}

1. Xu W, Judge MP, Maas K, Hussain N, McGrath JM, Henderson WA, et al. Systematic review of the effect of enteral feeding on gut microbiota in preterm infants. $J$ Obstet Gynecol Neonatal Nurs. 2018;47(3):45163. https://doi.org/10.1016/j.jogn.2017.08.009 PMid:29040820 
2. Inchingolo $F$, Santacroce $L$, Cantore $S$, Ballini A, Del Prete R, Topi S, et al. Probiotics and EpiCor ${ }^{\circledR}$ in human health. J Biol Regul Homeost Agents. 2019;33:1973-9. PMid:31858774

3. Santacroce L, Sardaro N, Topi S, Pettini F, Bottalico L, Cantore S, et al. The pivotal role of oral microbiota in health and disease. J Biol Regul Homeost Agents. 2020;34(2):733-7. PMid:32492992

4. Samuel TM, Sakwinska O, Makinen K, Burdge GC, Godfrey KM Silva-Zolezzi I. Preterm birth: A narrative review of the current evidence on nutritional and bioactive solutions for risk reduction. Nutrients. 2019;11(8):1811. https://doi.org/10.3390/nu11081811 PMid:31390765

5. Santacroce L, Bottalico L, Topi S, Castellaneta F, Charitos IA. The "Scourge of the Renaissance". A Short Review About Treponema pallidum infection. Endocr Metab Immune Disord Drug Targets. 2020;20(3):335-343. doi: 10.2174/18715303196 66191009144217

PMid: 31625831.

6. Santacroce L, Charitos IA, Bottalico L. A successful history: Probiotics and their potential as antimicrobials. Expert Rev Anti Infect Ther. 2019;17(8):635-45. https://doi.org/10.1080/14787210.2019.1645597 PMid:31318576

7. Laitinen K, Poussa T, Isolauri E. Probiotics and dietary counselling contribute to glucose regulation during and after pregnancy: A randomised controlled trial. $\mathrm{Br} \mathrm{J}$ Nutr. 2009;101(11):167987. PMid: 19017418 https://doi.org/10.1017/s0007114508111461

8. Tatullo M, Marrelli M, Scacco S, Lorusso M, Doria $S$, Sabatini $\mathrm{R}$, et al. Relationship between oxidative stress and burning mouth syndrome in female patients: A scientific hypothesis. Eur Rev Med Pharmacol Sci. 2012;16(9):1218-21. PMid:23047505

9. Marrelli $M$, Maletta $C$, Inchingolo $F$, Alfano $M$, Tatullo M. Three-point bending tests of zirconia core/ veneer ceramics for dental restorations. Int J Dent. 2013;2013:831976. https://doi.org/10.1155/2013/831976 PMid:23533415

10. Milman N, Paszkowski T, Cetin I, Castelo-Branco C. Supplementation during pregnancy: Beliefs and science. Gynecol Endocrinol. 2016;32(7):509-16. https://doi.org/10.3109/09513590.2016.1149161 PMid:26956254

11. Gluckman PD, Hanson MA, Mitchell MD. Developmental origins of health and disease: Reducing the burden of chronic disease in the next generation. Genome Med. 2010;2(2):14. https://doi.org/10.1186/gm135 PMid:20236494

12. Haider BA, Bhutta ZA. Multiple-micronutrient supplementation for women during pregnancy. Cochrane Database Syst Rev. 2017;4(4):CD004905. https://doi.org/10.1002/14651858.cd004905.pub5 PMid:28407219

13. Rautava S, Kalliomäki M, Isolauri E. Probiotics during pregnancy and breast-feeding might confer immunomodulatory protection against atopic disease in the infant. J Allergy Clin Immunol. 2002;109(1):119-21. https://doi.org/10.1067/mai.2002.120273 PMid:11799376

14. Kalliomäki M, Salminen S, Poussa T, Isolauri E. Probiotics during the first 7 years of life: A cumulative risk reduction of eczema in a randomized, placebo-controlled trial. J Allergy Clin Immunol. 2007;119(4):1019-21. https://doi.org/10.1016/j.jaci.2006.12.608 PMid: 17289135

15. Man A, Ciurea CN, Pasaroiu D, Savin Al, Toma F, Sular F, Santacroce L, Mare A. New perspectives on the nutritional factors influencing growth rate of Candida albicans in diabetics.
An in vitro study. Mem Inst Oswaldo Cruz. 2017 Sep;112(9):587592. doi: 10.1590/0074-02760170098.

PMid: 28902283

16. Paduano $F$, Marrelli $M$, Alom N, Amer M, White LJ, Shakesheff KM, et al. Decellularized bone extracellular matrix and human dental pulp stem cells as a construct for bone regeneration. J Biomater Sci Polym Ed. 2017;28(8):73048. $\quad$ https://doi.org/10.1080/09205063.2017.1301770 PMid:28285576

17. Mantaring J, Benyacoub J, Destura R, Pecquet S, Vidal K, Volger $\mathrm{S}$, et al. Effect of maternal supplement beverage with and without probiotics during pregnancy and lactation on maternal and infant health: A randomized controlled trial in the Philippines. BMC Pregnancy Childbirth. 2018;18(1):193. https://doi.org/10.1186/s12884-018-1828-8 PMid:29855271

18. LeeCS, Kim SH.Anti-inflammatory and anti-osteoporotic potential of Lactobacillus plantarum A41 and L. fermentum SRK414 as probiotics. Probiotics Antimicrob Proteins. 2020;12(2):623$34 . \quad$ https://doi.org/10.1007/s12602-019-09577-y PMid:31372901

19. Ballini A, Cantore S, Scacco S, Coletti D, Tatullo M. Mesenchymal stem cells as promoters, enhancers, and playmakers of the translational regenerative medicine. Stem Cells Int. 2018;2018:6927401. https://doi.org/10.1155/2018/6927401 PMid:30510586

20. Kerativitayanan P, Tatullo M, Khariton M, Joshi P, Perniconi B, Gaharwar AK. Nanoengineered osteoinductive and elastomeric scaffolds for bone tissue engineering. ACS Biomater Sci Eng. 2017;3:590-600. https://doi.org/10.1021/ acsbiomaterials.7b00029

21. Van Sande H, Jacquemyn $\mathrm{Y}$, Karepouan N, Ajaji M. Vitamin B12 in pregnancy: Maternal and fetal/neonatal effects. A review. Open J Obstetr Gynecol. 2013;3(7):599-602. https://doi. org/10.4236/ojog.2013.37107

22. Bardosono S, Wibowo N, Sutanto LB, Irwinda R, Cannan R, Rowan A, et al. Plasma folate, Vitamin B6 and B12 in their relationship to the presence of probiotic strain Bifidobacterium animalis subsp. Lactis HNO19 (DR10TM) among Indonesian pregnant women in their third semester. World Nutr J. 2018;2(2):56. https://doi.org/10.25220/wnj.v02.i2.0009

23. Kijmanawat A, Panburana P, Reutrakul S, Tangshewinsirikul C. Effects of probiotic supplements on insulin resistance in gestational diabetes mellitus: A double-blind randomized controlled trial. J Diabetes Investig. 2019;10(1):163-70. https://doi.org/10.1111/jdi.12863 PMid:29781243

24. Barry M, Pearce H, Cross L, Tatullo M, Gaharwar AK. Advances in nanotechnology for the treatment of osteoporosis. Curr Osteoporos Rep. 2016;14(3):8794. https://doi.org/10.1007/s11914-016-0306-3 PMid:27048473

25. Ballini A, Santacroce L, Cantore S, Bottalico L, Dipalma G, Topi S, et al. Probiotics efficacy on oxidative stress values in inflammatory bowel disease: A randomized double-blinded placebo-controlled pilot study. Endocr Metab Immune Disord Drug Targets. 2019;19(3):373-81. https://doi.org/10.2174/1871530319666181221150352 PMid:30574857

26. Campanella V, Syed J, Santacroce L, Saini R, Ballini A, Inchingolo F. Oral probiotics influence oral and respiratory tract infections in pediatric population: A randomized double-blinded placebo-controlled pilot study. Eur Rev Med Pharmacol Sci. 2018;22(22):8034-41. PMid:30536353

27. Ballini A, Santacroce L, Cantore S, Bottalico L, Dipalma G, Vito $D$, et al. Probiotics improve urogenital health in 
women. Open Access Maced J Med Sci. 2018;6(10):1845-

50. PMid:30455760

28. Ballini A, Gnoni A, De Vito D, Dipalma G, Cantore S, Isacco CG, et al. Effect of probiotics on the occurrence of nutrition absorption capacities in healthy children: A randomized double-blinded placebo-controlled pilot study. Eur Rev Med Pharmacol Sci. 2019;23(19):864557. https://doi.org/10.2174/1871530319666181221150352 PMid:31646599

29. Cicinelli E, Ballini A, Marinaccio M, Poliseno A, Coscia MF, Monno R, et al. Microbiological findings in endometrial specimen: Our experience. Arch Gynecol Obstet. 2012;285(5):13259. https://doi.org/10.1007/s00404-011-2138-9 PMID:22113463

30. Prete RD, Ronga L, Addati G, Magrone R, Abbasciano A, Carlo DD, et al. A retrospective study about the impact of switching from nested PCR to multiplex real-time PCR on the distribution of the human papillomavirus (HPV) genotypes. Medicina (Kaunas). 2019;55(8):418. https://doi.org/10.3390/medicina55080418 PMid:31366156
31. Coscia MF, Monno R, Ballini A, Mirgaldi R, Dipalma G, Pettini $F$, et al. Human papilloma virus (HPV) genotypes prevalence in a region of South Italy (Apulia). Ann Ist Super Sanita. 2015;51(3):248-51. PMid:26428051

32. Inchingolo F, Dipalma G, Cirulli N, Cantore S, Saini RS, Altini $\mathrm{V}$, et al. Microbiological results of improvement in periodontal condition by administration of oral probiotics. J Biol Regul Homeost Agents. 2018;32(5):1323-8. PMid:30334433

33. Cantore S, Ballini A, Mori G, Dibello V, Marrelli M, Mirgaldi $\mathrm{R}$, et al. Anti-plaque and antimicrobial efficiency of different oral rinses in a 3-day plaque accumulation model. J Biol Regul Homeost Agents. 2016;30(4):1173-8. PMid:28078871

34. Cantore S, Mirgaldi R, Ballini A, Coscia MF, Scacco S, Papa $F$, et al. Cytokine gene polymorphisms associate with microbiogical agents in periodontal disease: our experience. Int J Med Sci. 2014;11(7):674-9. https://doi.org/10.7150/ijms.6962 PMid:24843315 